\title{
Modafinil does enhance cognition, review finds
}

In the last paragraph of this News story (BMJ 2015;351:h4573, doi:10.1136/bmj.h4573), we incorrectly said that modafinil "is now out of patent and produced by a number of generic companies as Provigil." In fact, Provigil is the brand name and ๑ BMJ Publishing Group Ltd 2015 modafinil the generic name. 